American Journal of Agricultural and Biological Sciences 3 (2): 494-496, 2008

ISSN 1557-4989

(C) 2008 Science Publications

\title{
Diagnostic Utility of Nodular Gastritis in Children with Chronic Abdominal Pain Undergoing Endoscopy
}

\author{
${ }^{1}$ Seddiqe Amini-Ranjbar and ${ }^{2}$ Nouzar Nakhaee \\ ${ }^{1}$ Department of Pediatrics, ${ }^{2}$ Kerman Neuroscience Research Center, \\ Kerman University of Medical Sciences, Iran
}

\begin{abstract}
This study was aimed to describe the endoscopic picture and laboratory findings in children with chronic abdominal pain and to determine the utility of nodular gastritis in diagnosing HPI in these patients. This prospective study was done between November, 2004 and May, 2007. A total of 70 patients (36 male and 34 female) aged 3-14 years, underwent upper endoscopy. H-pylori infection was diagnosed when both urease test and histology were positive for the infection. Seventy percent $(n=49)$ of them were diagnosed to have endoscopic nodular gastritis. HPI was confirmed in 33 (47.1\%) of 70 patients. The endoscopic antral nodularity had a sensitivity of $100 \%$, specificity of $56.8 \%$, positive predictive value of $67.3 \%$, negative predictive value of $100 \%$ and a positive LR of 2.32 for diagnosis of HPI. It may be recommended that if nodular gastritis observed in a pediatric patient with chronic abdominal pain he/she should be investigated to exclude HPI otherwise no further work up is necessary to confirm HPI.
\end{abstract}

Key words: Antral nodularity, endoscopic examination, gastritis

\section{INTRODUCTION}

In children, Helicobacter pylori (HPI) is usually colonized before the age of 5 and if not cured it will last Lifelong. This phenomenon is specially more common in developing countries and affects up to $80 \%$ of children under the age of $10^{[1]}$. HPI is the most common cause of chronic gastritis, gastric ulcer $(25 \%)$ and duodenal ulcer $(90 \%)^{[2,3]}$. This micro-organism is observed in 30-100 percent of children with endoscopic nodular gastritis ${ }^{[2]}$. It is found in the gastric mucosa or attached to the epithelial lining of only the human stomach $^{[4]}$. The role of this pathogen in gastric cancer and maltoma is well known ${ }^{[2,5]}$.

Upper gastrointestinal endoscopy is the diagnostic method of choice to confirm presence of nodular gastritis in the antral area of the stomach ${ }^{[6,7]}$. Nodular gastritis is defined as antral gastritis usually characterized by a unique military pattern resembling gooseflesh on endoscopy representing increased numbers of lymphoid follicles with germinal center ${ }^{[1]}$. Endocscopy frequently shows antral nodularity in infected children ${ }^{[6]}$. Nodular gastritis is found both in children with and without gastric ulcer ${ }^{[1]}$. Nodular gastritis is in favor of high colonization of HPI in children, as far as some authors have considered antral nodularity spesific for HPI in children ${ }^{[8]}$, on the other hand some authors have brougth into question the specificity of this finding in relation to $\mathrm{HPI}^{[9,10]}$. Due to
H-pylori's fastidious requirements, routine culture is very difficult in a clinical practice. A more practical gold standard for the diagnosis of H-pylori is either a positive culture or the identification of its on both histhology and urease testing ${ }^{[11]}$.

Thus, considering the disputable relation of antral nodularity with $\mathrm{H}$-pylori and its diagnostic dilemmas in pediatric patients, this study was conducted to identify the endoscopic picture and laboratory findings in children with chronic abdominal pain and to determine the utility of nodular gastritis in diagnosing HPI in these patients.

\section{MATERIALS AND METHODS}

Between November, 2004 and May, 2007 this study was prospectively done on 70 children between 3 to 14 years old who had referred to a tertiary care outpatient center with chief complaint of chronic abdominal pain. The children who had consumed antibiotics and antiacids in the recent month were excluded from the study. After obtaining informed consent from the parents the patients underwent upper gastrointestinal endoscopy by pediatric gastroenterologist. Four biopsy specimens were taken from antrum and body of stomach in order to perform urease test and pathologic study. The color change from yellow to pink-red (red-violet) in maximum $24 \mathrm{~h}$ was considered positive ${ }^{[1,2]}$. Antral nodularity was referred 
to as a situation that antral mucousa was observed in the form of stone pavement appearance in endoscopy ${ }^{[9,10]}$. The Giemsa stain was applied for detection of H-pylori. A child was diagnosed infected when urease test and histhology simultaneously were positive.

The sensitivity, specificity, positive predictive value, negative predictive value and positive likelihood ratio (LR), were calculated based on standard formula ${ }^{[12]}$. Chi square test was used to compare categorical variables. Statistical analyses were done by SPSS V.15.

\section{RESULTS AND DISCUSSION}

The mean $( \pm \mathrm{SD})$ age of subjects was $9.5( \pm 1.5)$ .The majority $(85.7 \%)$ of them were six years old or over. Fifty one percent $(n=36)$ were male. Seventy percent $(n=49)$ of them were diagnosed to have endoscopic nodular gastritis (Table 1). Six $(8.5 \%)$ of children in addition to abdominal pain, suffered from non-variceal upper gastrointestinal bleeding. Most $(77.5 \%)$ of those who had nodular gastritis, simultaneously had positive urease test too (Table 1). HPI was confirmed in 33 (47.1\%) individuals (Table 1). None of the 21 children who endoscopically were normal or mucusal erythema or superficial erosion were diagnosed on endoscopy, had HPI (Table 1).

The majority $(91.8 \%)$ of those who had antral nodularity and $90.9 \%$ of children who had HPI were 6 years old or over (Table 2). The rate of antral nodularity $(\mathrm{p}=0.14)$ and HPI $(\mathrm{P}=0.98)$ were not different according to the sex of the patients (Table 2). Seventy five percent of patients older than five years age showed the pattern of nodular gastritis on endoscopy, whilst the rate was lower in the younger age group (Table 2).

The endoscopic antral nodularity had a sensitivity of $100 \%$, specificity of $56.8 \%$, positive predictive value of $67.3 \%$, negative predictive value of $100 \%$ and a positive LR of 2.32 for diagnosis of HPI.

Despite the $57 \%$ positive rate of urease test in all children with chronic abdominal pain only $47 \%$ had HPI and those with normal endoscopy or minimal abnormality (i.e., mucosal erythema) showed no HPI. All the cases of positive HPI were diagnosed in patients who had antral nodularity in their endoscopic examination. So exploring the relationship of HPI and antral nodularity may be informative in clinical decision making for children with chronic abdominal pain.

According to the existing literature nodular gastritis in the children with chronic abdominal pain who are infected with H-pylori is common ${ }^{[6]}$ as far as some authors report are concerned, about 30-100 percent of children affected with nodular gastritis suffer from $\mathrm{HPI}^{[2,13]}$.

Table 1: The result of urease test and pathologic diagnosis based on endoscopic classification of pediatric patients with chronic abdominal pain

\begin{tabular}{|c|c|c|c|c|c|c|}
\hline \multirow{2}{*}{$\begin{array}{l}\text { Paraclinical study } \\
\text { Endosopic findings }\end{array}$} & \multicolumn{2}{|c|}{ Positive urease test } & \multicolumn{2}{|c|}{ Positive pathology } & \multicolumn{2}{|c|}{ Positive urease test \& pathology } \\
\hline & No. & $\%$ & No. & $\%$ & No. & $\%$ \\
\hline Normal $(n=13)$ & 1 & 7.6 & 1 & 7.6 & 0 & 0 \\
\hline Antral nodularity $(\mathrm{n}=49)$ & 38 & 77.5 & 33 & 67.3 & 33 & 67.3 \\
\hline Mucosal erythema $(n=4)$ & 0 & 0 & 2 & 50 & 0 & 0 \\
\hline Superficial gastric/duodenal erosion $(n=4)$ & 1 & 25 & 0 & 0 & 0 & 0 \\
\hline Gastric/Duodenal ${ }^{*}$ ulcer and antral nodularity $(\mathrm{n}=3)$ & 3 & 100 & 3 & 100 & 3 & 100 \\
\hline Total $(\mathrm{n}=70)$ & 40 & 57.1 & 36 & 51.4 & 33 & 47.1 \\
\hline
\end{tabular}

${ }^{*}$ Values of this row are not included in the sum owing to duplication

Table 2: Frequency distribution of antral nodularity and H-pylori infection in children with chronic abdominal pain according to age group and

\begin{tabular}{|c|c|c|c|c|c|c|c|}
\hline \multirow[b]{2}{*}{ Basic change } & & \multicolumn{3}{|c|}{ Antral nodularity } & \multicolumn{3}{|c|}{ H-pylori infection } \\
\hline & & Positive & negative & $\mathrm{P}$ & positive & negative & $\mathrm{P}$ \\
\hline \multirow[t]{2}{*}{ Age group } & $\begin{array}{l}<6 \text { years old } \\
(\mathrm{n}=10)\end{array}$ & $4(40)$ & $6(60)$ & & $3(30)$ & $7(70)$ & \\
\hline & $\begin{array}{l}\geq 6 \text { years old } \\
(\mathrm{n}=60)\end{array}$ & $45(75)$ & $15(25)$ & 0.06 & $30(50)$ & $30(50)$ & 0.31 \\
\hline \multirow[t]{2}{*}{ Sex } & $\begin{array}{l}\text { Male } \\
(\mathrm{n}=36)\end{array}$ & $28(77.8)$ & $8(22.2)$ & & $17(47.2)$ & $19(52.8)$ & \\
\hline & $\begin{array}{l}\text { Female } \\
(n=34)\end{array}$ & $21(61.8)$ & $13(38.2)$ & 0.14 & $16(47.1)$ & $18(52.9)$ & 0.98 \\
\hline
\end{tabular}


As it is inferred from the present study antral nodularity was a common finding $(70 \%)$ in the Iranian children who were presented by abdominal pain.

The rate of HPI was $47.7 \%$ in our study which is comparable to another study conducted in Iran $(46 \%)^{[10]}$, but is higher than figures reported in other studies. Estimates show that the prevalence of HPI in pediatric patients suffering from chronic abdominal pain in different countries differs; Taiwan $(23.7 \%)^{[14]}$, Thailand $(15.2 \%)^{[13]}$, Brazil $(27 \%)^{[9]}$ and Japan $(16.4 \%)^{[5]}$. These variations may be due to differences in personal hygiene, food and feeding habits and different settings of the studies ${ }^{[4]}$.

The sensitivity of antral nodularity in detecting $\mathrm{H}$ pylori has been $100 \%$, it means that all the children affected with abdominal pain who had been inflected with the H-pylori showed nodular gastritis on endoscopy so it can be concluded that if a patient had no antral nodularity during endoscopic investigation he/she would not be infected by H-pylori and on the other hand this endoscopic finding is not observed in 21 children affected with abdominal pain who were not affected with helicobacter in another word endoscopic nodular gastritis had a specificity of $56.8 \%$. Therefore considering the sensitivity and negative predictive value achieved in this study (i.e., 100\%), in children with abdominal pain who do not have nodular gastritis, the evaluation of child regarding HPI can be avoided. In other words in the absence of nodular gastritis the presence of HPI might be ruled out but the inverse is not true; owing to its relative low specificity this finding is not confirmatory for $\mathrm{HPI}^{[12]}$. The sensitivity and specificity of nodular gastritis in were 80 and $64 \%$, respectively in a study conducted in Northern Iran ${ }^{[10]}$ and the sensitivity has been reported $98.5 \%$ in another study performed on Brazilian patients ${ }^{[9]}$. The reason for these variations may be due to some differences in selecting the patients. A positive likelihood ratio of 2.3 tells us that antral nodularity is 2.3 times more likely to be found in a child with HPI than in a noninfected child $^{[10]}$. Positive LR less than 2 is regarded as unimportant $^{[10]}$.

In conclusion it may be recommended that if nodular gastritis observed in a pediatric patient with chronic abdominal pain he/she should be investigated to exclude HPI otherwise no further work up to confirm HPI is necessary.

\section{REFERENCES}

1. Walker, Goulet, Klieinman, Sherman, Shneider and Sanderson, 2004. Pediatric Gastrointestinal Disease. $4^{\text {th }}$ Ed., pp: 493,494,498 and 499.
2. Hong Koh, N. Tae-Woong, B. Seoung-Yon and C. Ki- Sup, 2007. Nodular gastritis and pathologic findings in children and young adult with Helicobacter pylori infection. Yonsei Med. J., pp: 240-46.

3. Macarthur, C., N. Saunders and W. Feldman, 1995. Helicobacter pylori, gastroduodenal disease and recurrent abdominal pain in children. JAMA., 273: 729-34.

4. Logan, R.P., M.M. Walker, 2001. ABC of the upper gastrointestinal tract: Epidemiology and diagnosis of Helicobacter pylori infection. BMJ., 20, 323 (7318): 920-2.

5. Shimatani, T., M. Inoue, K. Iwamoto, H. Hyogo, M. Yokazaki, T. Saeki, S. Tazuma and Y. Horikawa, 2005. Pevalence of Helicobacter pylori infection, endoscopic gastric findings and dyspeptic syptoms among a young Japanese population born in the 1970 s. J. Gastroenterol. Hepatol., pp: 1352-57.

6. Behrman, R.E. and R.M. Kliekman, 2004. Nelson. Textbook of pediatric. $17^{\text {th }}$ Edn., pp: $1245-46$.

7. Okello, T.R, 2006. Upper gatrointestinal endoscopic findings in adolescents at Locor hospital, Uganda. African Health Sciences., 39-42.

8. Serban, R., P. Grigorescu-Sido, D. Gheban and E. Kiss, 2002. Helicobacter pylori gastritis in children: Endoscopic and histological aspect. Rom. J. Gastroenterol., 11 (4): 297-301.

9. Bahu Mda, G., T.R. da Silveira, I. Maguilnick and J. Ulbrich-Kulczynski, 2003.Endoscopic nodular gastritis: An endoscopic indicator of high- grade bacterial colonization and severe gastrtis in children with Helicobacter pylori. J. Pediatr. Gastroenterol. Nutr., 36: 217-22.

10. Rafeey, M., A.H. Jafari Rouhi, B.A. Gassemi and A. Jafari Rouhi, 2004. Relationship between endoscopic nodular gastritis and Helicobacter pylori infection in children. Indian $\mathrm{J}$. Gastroenterol., 138-39.

11. Ricci, C., J. Holton and D. Vaira, 2007. Diagnosis of Helicobacter pylori: Invasive and non-invasive tests. Best. Pract. Res. Clin. Gastroenterol., 21 (2): 299-313.

12. Chu, K., 1999. An introduction to sensitivity, specificity, predictive values and likelihood ratios. Emerg. Med., 11, 175-181.

13. Vithavasai, N., 2003. Childhood Helicobacter pylori infection, clinical presentation, endoscopic, histhologic features and results of treatment. J. Med .Assoc .Thai., 3: 600-4.

14. Lin, M.H., L.K. Chen, S.G. Hwang and T.C. Wu, 2006. Childhood functional abdominal pain and Helicobacter pylori infection. Hepatogasteroenterol., 53 (72): 883-6. 